\title{
Acute periostitis in early acquired syphilis
}

\author{
R. B. ROY AND S. M. LAIRD \\ Special Clinic, Royal Victoria Hospital, Bournemouth, Hants.
}

Acute periostitis affecting the long bones is a characteristic and not uncommon feature of syphilis in infants; it is, however, a rare manifestation in the adult with early acquired infection.

\section{Case report}

A white married man, aged 33 years was treated for penile warts between February and July, 1971. Serological tests for syphilis (WR, VDRL, and RPCF) were negative at his first attendance. He was admitted to hospital on October 1, 1971, for incision of a peri-anal abscess; the serological tests for syphilis were now found to be positive (VDRL titre 1:16) and the erythrocyte sedimentation rate was raised $(66 \mathrm{~mm} . / 1 \mathrm{st} \mathrm{hr})$. About this time he began to experience intermittent pains in both tibiae which were most severe when he was inactive sitting in front of a fire or after a hot bath. Radiographs of the tibiae were inconclusive.

Examination in the clinic on December 7, 1971, revealed:

(1) An early, faint, macular syphilide on the trunk, arms, and soles of the feet

(2) No anal or genital lesions except for a few small penile warts

(3) For $10 \mathrm{~cm}$. over the anterior surface of both tibiae a slight pitting oedema of the skin with a small, very localized central area of exquisite tenderness.

The pain and the signs of periostitis disappeared within $48 \mathrm{hrs}$ of starting treatment with penicillin and a Herxheimer reaction occurred.

The patient's wife was found to be, and to remain, free from syphilis, and it is probable that the infection was acquired homosexually.

\section{Discussion}

Hutchinson (1887) has reported two male adults who presented with acute periostitis of the tibiae during the early secondary stage of acquired syphilis; the periostitis was bilateral in one case but unilateral in the other. It is perhaps of interest that the pain in the unilateral case responded within one week of starting treatment with potassium iodide and the other case also responded well to unspecified treatment (probably mercury). Stokes (1934) stated that early syphilitic periostitis was clinically a sharply

Received for publication April 17, 1973 localized process presenting as a doughy elevation, non-inflammatory and with no sign of fluctuation; the anterior face and edge of the tibia is most often involved and the most distinctive feature is a localized point of exquisite tenderness. The pain is exaggerated by heat and reduced by movement. The case reported here presented the typical signs described by Stokes. The patient worked hard as a plasterer and was physically active at the weekends when he acted as a football referee, without experiencing much pain, but after a hot bath or whilst sitting in front of a fire the tibial pain became very severe. King and Nicol (1964) stated that the osteocopic pains in the secondary stage are due to periostitis, but that it was rare to find objective signs of periostitis at this stage of the disease. It is generally agreed that this early periostitis produces no definite radiological changes. The whole subject of syphilis of bones has been well reviewed by King and Catterall (1959).

\section{Summary}

The case is reported of a man who developed acute, localized periostitis of the shaft of both tibiae during the early secondary stage of acquired syphilis. The signs and symptoms faithfully portrayed the clinical picture described by Stokes.

\section{References}

Hutchinson, J. (1887) 'Syphilis', Commentaries 32 and 33, pp. 142-4. Cassell, London

King, A. J., and Catterall, R. D. (1959) Brit. F. vener. Dis., 35, 116

— and Nicol, C. S. (1964) 'Venereal Diseases', p.24. Cassell, London

Stokes, J. H. (1934) 'Modern Clinical Syphilology', 2nd ed., p.687. Saunders, Philadelphia

\section{Périostite aigüe dans la syphilis acquise récente}

On rapporte l'observation d'un homme chez qui apparut une périostite aigüe localisée du corps des deux tibias au cours du stade secondaire précoce de la syphilis acquise. Les signes et les symptômes correspondaient fidèlement à la description clinique de Stokes. 